\title{
Infrared-reflectance spectra of heat-treated, sol-gel-derived silica
}

\author{
E. I. Kamitsos and A. P. Patsis \\ Theoretical and Physical Chemistry Institute, National Hellenic Research Foundation, \\ 48 Vassileos Constantinou Avenue, 11635 Athens, Greece \\ G. Kordas \\ National Centre for Scientific Research “Demokritos,” Institute of Materials Science, 15330 Agia Paraskevi Attikis, Greece
}

(Received 29 January 1993)

\begin{abstract}
The infrared-reflectance spectra of silica glasses were measured and analyzed with a Kramers-Kronig transformation for a better understanding of the response of silica, especially in the high-frequency region $\left(1000-1300 \mathrm{~cm}^{-1}\right)$. The silica samples were prepared by the sol-gel technique and subsequently subjected to heat treatments at selected temperatures to induce the formation of structures with a variable connectivity of the silicate network. The infrared reflectivity was found to increase with heattreatment temperature. This was attributed to glass densification, resulting from condensation of Si-OH groups into Si-O-Si network bridging units. This densification mechanism was also confirmed by Raman measurements. The profiles of the high-frequency parts of the transverse-optic (TO) and longitudinaloptic (LO) spectra were found consistent with the presence of two coupled modes $\left(\mathrm{AS}_{1}\right.$ and $\left.\mathrm{AS}_{2}\right)$ for the asymmetric stretching of $\mathrm{Si}-\mathrm{O}-\mathrm{Si}$ bridges, as proposed in previous works. Along these lines, the shoulder at $\sim 1200 \mathrm{~cm}^{-1}$ in the infrared-absorption spectrum of silica, which is particularly enhanced in the spectra of silica gels, can be understood as arising from the TO response of the $\mathrm{AS}_{2}$ mode. The LO-TO splitting of the various infrared-active modes was found to depend on heat-treatment temperature. This effect was attributed to variations of silicate network connectivity with temperature, which is presumably affecting the range of the Coulombic forces inducing the LO-TO splitting.
\end{abstract}

\section{INTRODUCTION}

Sol-gel-derived silica glass is a widely studied material due to its applications in optics, electronics, and other fields of technology. 1,2 Various experimental techniques have been employed to understand the mechanism of gel-to-glass transition in $\mathrm{SiO}_{2}$ in order to find ways of improving the quality of the prepared material. ${ }^{3}$ Among the spectroscopic techniques, infrared spectroscopy is probably one of the most extensively used to investigate the structure of amorphous $\mathrm{SiO}_{2}$ prepared by the sol-gel process $^{4-14}$ as well as by other methods. ${ }^{15-26}$ The latter include conventional melting and quenching, ${ }^{15-19}$ thermal growth, ${ }^{20-25}$ and chemical vapor deposition (CVD). ${ }^{26}$

Despite the numerous infrared studies devoted to amorphous $\mathrm{SiO}_{2}$, there is considerable controversy concerning the origin of high-frequency absorption peaks between $\sim 1000$ and $1300 \mathrm{~cm}^{-1}$. The infrared absorption spectrum of $\mathrm{SiO}_{2}$, measured at normal incidence of the radiation, exhibits at high frequencies a strong band at $\sim 1080 \mathrm{~cm}^{-1}$ and a shoulder at $\sim 1200 \mathrm{~cm}^{-1}$. The exact position of the $\sim 1080 \mathrm{~cm}^{-1}$ feature depends strongly on the oxygen content in the case of thermally grown and CVD $\mathrm{SiO}_{2}$ films ${ }^{22,26}$ and on the heat treatment temperature of $\mathrm{SiO}_{2}$ gels. ${ }^{3,10,13}$ The spectra of the latter materials exhibit a particularly strong $1200 \mathrm{~cm}^{-1}$ shoulder. Its intensity decreases with increasing temperature of treatments of the gel. ${ }^{11}$ The nature of this shoulder has been related to the longitudinal-optic (LO) component of the asymmetric stretching vibration of $\mathrm{Si}-\mathrm{O}-\mathrm{Si}$ bridges ${ }^{5,11}$ with its transverse-optic (TO) pair giving rise to the strong absorption at $\sim 1080 \mathrm{~cm}^{-1} \cdot{ }^{17,19}$ Almeida and Pantano ${ }^{11}$ suggested that there are probably no pure TO and LO modes in amorphous materials due to long-range disorder. This effect was thought to cause an admixture of LO character in the TO response. Along these lines, the enhanced intensity of the $1200 \mathrm{~cm}^{-1}$ shoulder in the spectra of gels was attributed to the porous nature of these materials, which effectively scatter the normal incidence light and cause a substantial fraction of it to enter at oblique incidence and to increase the LO character in the TO spectra. ${ }^{11}$

A different assignment for the $1200 \mathrm{~cm}^{-1}$ shoulder of the normal incidence absorption spectra was originally proposed by Gaskell and Johnson ${ }^{16}$ and found subsequent support by $\mathrm{Kirk}^{25}$ and Lucovsky and co-workers. ${ }^{26,27}$ In particular, it was shown that the asymmetric stretching (AS) of Si-O-Si bridges that involves motion of the oxygen atom parallel to the $\mathrm{Si}-\mathrm{Si}$ direction, gives rise to two vibrational modes. In one mode, $\mathrm{AS}_{1}$, adjacent oxygen atoms execute the AS motion in phase with each other and in the other mode, $\mathrm{AS}_{2}$, adjacent oxygen atoms execute the AS motion $180^{\circ}$ out of phase. It was proposed that the TO response of the $\mathrm{AS}_{1}$ mode is centered at $\sim 1080 \mathrm{~cm}^{-1}$, while the TO response of the $\mathrm{AS}_{2}$ mode is responsible for the shoulder at $\sim 1200 \mathrm{~cm}^{-1} \cdot 16,25-27$

Absorption measurements on thin $\mathrm{SiO}_{2}$ films under oblique incidence of $p$-polarized light (one component of the electric vector is parallel and another perpendicular to the plane of the film) revealed strong absorptions at $\sim 1080$ and $1260 \mathrm{~cm}^{-1} \cdot 21,25$ While the first band was attributed the TO response of the $\mathrm{AS}_{1}$ mode, the second feature at $1260 \mathrm{~cm}^{-1}$ was assigned to the LO component 
of the same mode. ${ }^{21,25}$ The activation of a band of LO character in the absorption spectrum excited with $p$ polarized light was explained on the basis of the wellknown Berreman effect. ${ }^{28}$ In addition, Kirk was able to identify the LO component of the $\mathrm{AS}_{2}$ mode at 1160 $\mathrm{cm}^{-1}$ with its TO partner being located at $1200 \mathrm{~cm}^{-1}$ for thermally grown $\mathrm{SiO}_{2}$ films on $c$-Si substrate. ${ }^{25}$

It is obvious that more work is required to resolve the existing disagreement in literature concerning the nature of the high-frequency features in the infrared spectrum of amorphous $\mathrm{SiO}_{2}$. This is especially important for solgel-derived silica materials, for which the combination of their inherent porous nature with thermal history effects, cause additional complications compared to conventional silica glass. ${ }^{3}$

To our knowledge, there is only one report concerning the infrared reflectance $\left(20^{\circ}\right.$ off normal) of an air-dried $\mathrm{SiO}_{2}$ gel. ${ }^{14}$ In that work, emphasis was placed on the observed redshift of the main peaks of the energy-loss spectrum of the gel compared to that of vitreous $\mathrm{SiO}_{2}$, and the relation of such shifts to the strain state of the Si-O-Si bridges at the surface of the gel pores. ${ }^{14}$

In this paper we report the results of an infrared reflectance study of $\mathrm{SiO}_{2}$ gels heat treated at selected temperatures, in an attempt to contribute towards a better understanding of the infrared response of silica glass. The reflectance spectra were recorded at nearly normal incidence $\left(11^{\circ}\right.$ off-normal) and were analyzed by Kramers-Kronig inversion to identify the TO and LO modes. It is known that the position of peaks in the imaginary part of the complex dielectric constant, $\varepsilon=\varepsilon^{\prime}+i \varepsilon^{\prime \prime}$, correspond to TO modes, while peaks in the energy-loss function, $-\operatorname{Im}(1 / \varepsilon)$, locate the LO modes. ${ }^{17,19}$ The same $\mathrm{SiO}_{2}$ gels studied by infrared reflectance were also investigated by Raman scattering to obtain complementary information on the structure of these materials.

\section{EXPERIMENT}

The silica gels were prepared according to published procedures $^{29}$ by hydrolysis and polycondensation of tetraethyl ortho silicate in water and/or ethanol solutions under acidic conditions. The gel samples were air dried at room temperature for extended periods of time. Some of the dried gels were subsequently heat treated from room temperature to $650^{\circ} \mathrm{C}$ at a rate of $2^{\circ} \mathrm{C} / \mathrm{min}$, and, others from room temperature to $1000^{\circ} \mathrm{C}$ at a rate of $8^{\circ} \mathrm{C} / \mathrm{min}$. The samples were maintained for $2 \mathrm{~h}$ at each temperature and subsequently quenched to room temperature by removing them from the furnace to open air. Three types of silica gel samples were thus investigated by infrared and Raman spectroscopy: air-dried gels (samples $A$ ), heat-treated gels at $650^{\circ} \mathrm{C}$ (samples $B$ ), and heat treated gels at $1000^{\circ} \mathrm{C}$ (samples $C$ ). The choice of the heat treatment temperatures employed in this study was based on the results of earlier investigations of the effect of heat treatment temperature on physical properties of silica gels, including pore size distribution, density, refractive index, and compression strength. ${ }^{12,29,30}$ These properties exhibit a considerable change in the range $600-700^{\circ} \mathrm{C}$, and approach the corresponding values of vitreous $\mathrm{SiO}_{2}$ at $1000^{\circ} \mathrm{C}$. For spectroscopic measurements samples with flat, smooth surfaces were selected and used without further treatment to avoid surface destruction.

Infrared reflectance spectra were measured on a Fourier-transform IR vacuum spectrometer (Bruker 113 v) equipped with an $11^{\circ}$ off-normal reflectance attachment. A combination of sources ( $\mathbf{H g}$ arc and globar), detectors (DTGS with $\mathrm{KBr}$ and polyethylene windows) and beam splitters ( $\mathrm{KBr}$ and mylar of variable thickness) was used to cover the mid- and far-infrared range. All spectra were measured at room temperature against a high reflectivity aluminum mirror. Each spectrum represents the average of 200 scans with $2 \mathrm{~cm}^{-1}$ resolution. The reflectivity data were analyzed by the Kramers-Kronig inversion, as previously described in details. ${ }^{31}$ Raman spectra were recorded on a Jobin Yvon HG 2S spectrometer using the $488.0 \mathrm{~nm}$ Ar-laser line for excitation $(200 \mathrm{~mW})$ at a $90^{\circ}$ scattering geometry.

\section{RESULTS AND DISCUSSION}

\section{A. Infrared reflectance and Raman spectra}

Figure 1 shows representative infrared reflectance spectra of an air-dried gel $(A)$, a heat-treated gel at

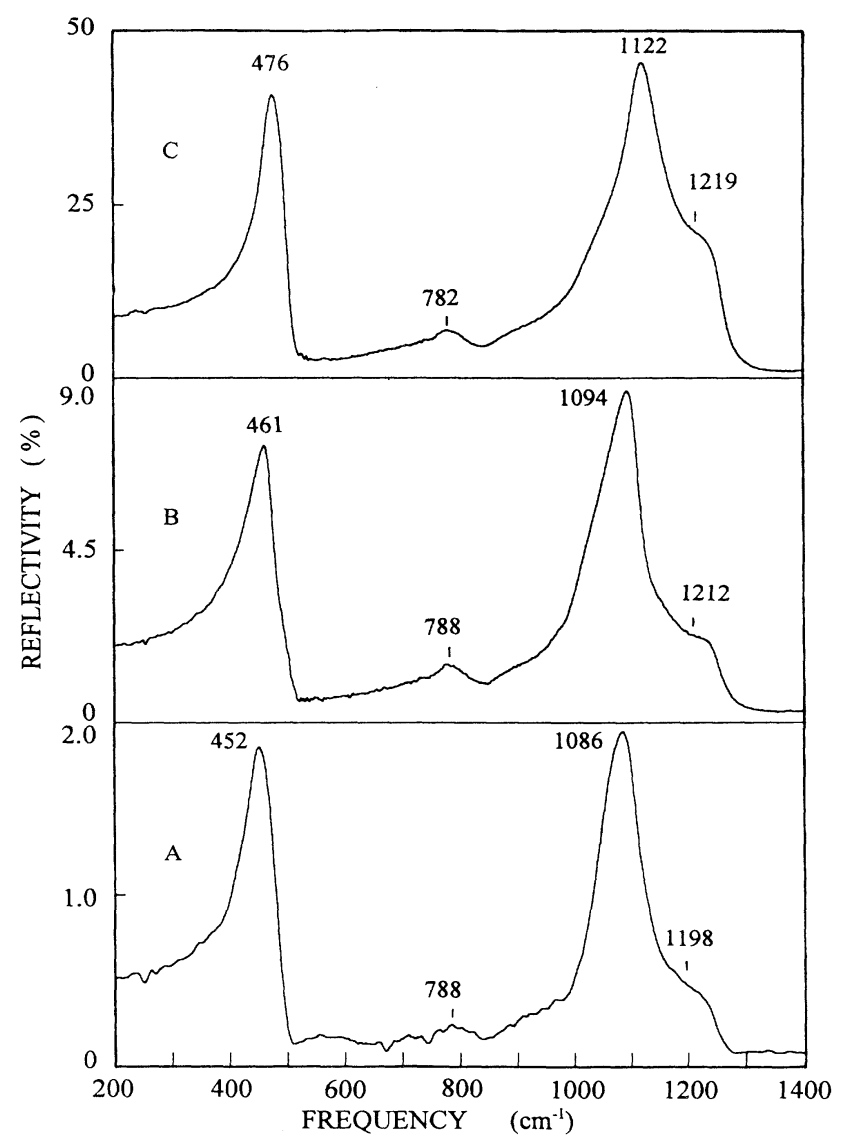

FIG. 1. Infrared-reflectance spectra of $\mathrm{SiO}_{2}$ gels heat-treated at different temperatures: $(A)$ air-dried, $(B) 650^{\circ} \mathrm{C}$, and $(C)$ $1000^{\circ} \mathrm{C}$. 
$650^{\circ} \mathrm{C}(B)$, and a heat-treated gel at $1000^{\circ} \mathrm{C}(C)$. All spectra exhibit three main reflectivity maxima at $\sim 460$, 785 , and $1100 \mathrm{~cm}^{-1}$. Bands at similar frequencies in the spectrum of vitreous $\mathrm{SiO}_{2}$ have been assigned to characteristic vibrations of the Si-O-Si bridges crosslinking the silicate network. Specifically, the $460 \mathrm{~cm}^{-1}$ feature was attributed to the rocking motion of the bridging oxygen atom perpendicular to the Si-O-Si plane, the $785 \mathrm{~cm}^{-1}$ band to the bending motion of the oxygen atom along the bisector of the Si-O-Si bridging group, and the highfrequency band peaking at $\sim 1100 \mathrm{~cm}^{-1}$ to the asymmetric stretching mode of Si-O-Si groups that involves mainly oxygen motion along the Si-Si direction. ${ }^{25-27}$

Even though the overall spectral profiles appear similar (Fig. 1), certain differences exist between the three spectra. First, it is observed that the two main reflectivity maxima at $\sim 460$ and $\sim 1100 \mathrm{~cm}^{-1}$ up shift gradually in frequency from the spectrum of the air-dried gel to that of the gel heat treated at $1000^{\circ} \mathrm{C}$. This frequency increase suggests a strengthening of the silicate network upon heat-treatment, resulting probably from the gradual densification of the gel. ${ }^{3}$ Second, the heat-treatment temperature affects strongly the gel reflectivity (Fig. 1). Thus, the reflectivity corresponding to the main peak at $\sim 1100 \mathrm{~cm}^{-1}$ is approximately $2 \%$ for the air-dried gel, $9 \%$ for that treated at $650^{\circ} \mathrm{C}$ and increases to $45 \%$ for the $1000^{\circ} \mathrm{C}$ treated gel. The corresponding reflectivity of Vycor glass and of vitreous silica is approximately $4 \%$ (Ref. 18) and 75\%, ${ }^{15-19}$ respectively.

The very low reflectivities of the air-dried and the $650^{\circ} \mathrm{C}$ treated gels, as well as that of Vycor glass ${ }^{18}$ are indicative of a porous open structure that effectively scatters the infrared light even at nearly normal incidence. Figure 2 supports a correlation between the porosity of the gel materials and their infrared reflectivity. In this figure, pore volume data reported by Krol and Lierop ${ }^{29}$ and density values reported by Yoshino, Kamiya, and Nasu ${ }^{12}$ on similarly prepared $\mathrm{SiO}_{2}$ gels, as well as the reflectivity corresponding to the main peak at $\sim 1100 \mathrm{~cm}^{-1}$ measured in this work are plotted versus the heat-treatment temperature of the $\mathrm{SiO}_{2}$ gel. Clearly, at $650^{\circ} \mathrm{C}$ the pore volume per gram $\mathrm{SiO}_{2}$ is considerably reduced, while the density and reflectivity show a substantial increase. At $1000^{\circ} \mathrm{C}$, the volume corresponding to pores in the gel is drastically reduced as the density approaches the value of fused silica and the infrared reflectivity increases sharply.

Figure 3 plots the Raman spectra of the same gel materials in order to assist identifying the molecular processes which lead to gel densification and thus reduction of porosity with increasing heat-treatment temperature. The general dependence of the Raman spectra on heattreatment temperature is in agreement with the results of previous studies. ${ }^{5,29,32-34}$ The spectrum of the air-dried gel [Fig. $3(A)$ ] shows a strong fluorescence background at high frequencies, despite the fact that neither the Raman nor the infrared spectrum show the presence of residual organics. Such a fluorescence may originate from an intrinsic electronic surface effect which was proposed to be particularly strong in materials with high surface area. ${ }^{18}$ The fluorescence background was eliminated in

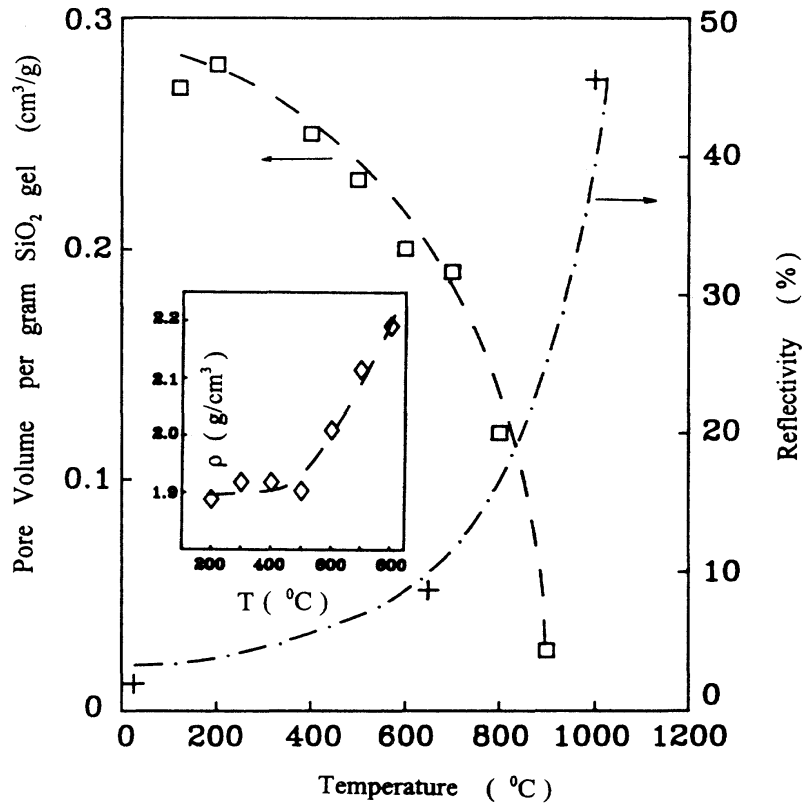

FIG. 2. Effect of increasing heat-treatment temperature on the pore volume, the density, and the infrared reflectivity of $\mathrm{SiO}_{2}$ gels. Pore volume data were obtained from Ref. (29) and density data from Ref. (12). The reflectivity values correspond to the reflectivity of the main peak at ca. $1100 \mathrm{~cm}^{-1}$. Lines through the data points are drawn to guide the eye.

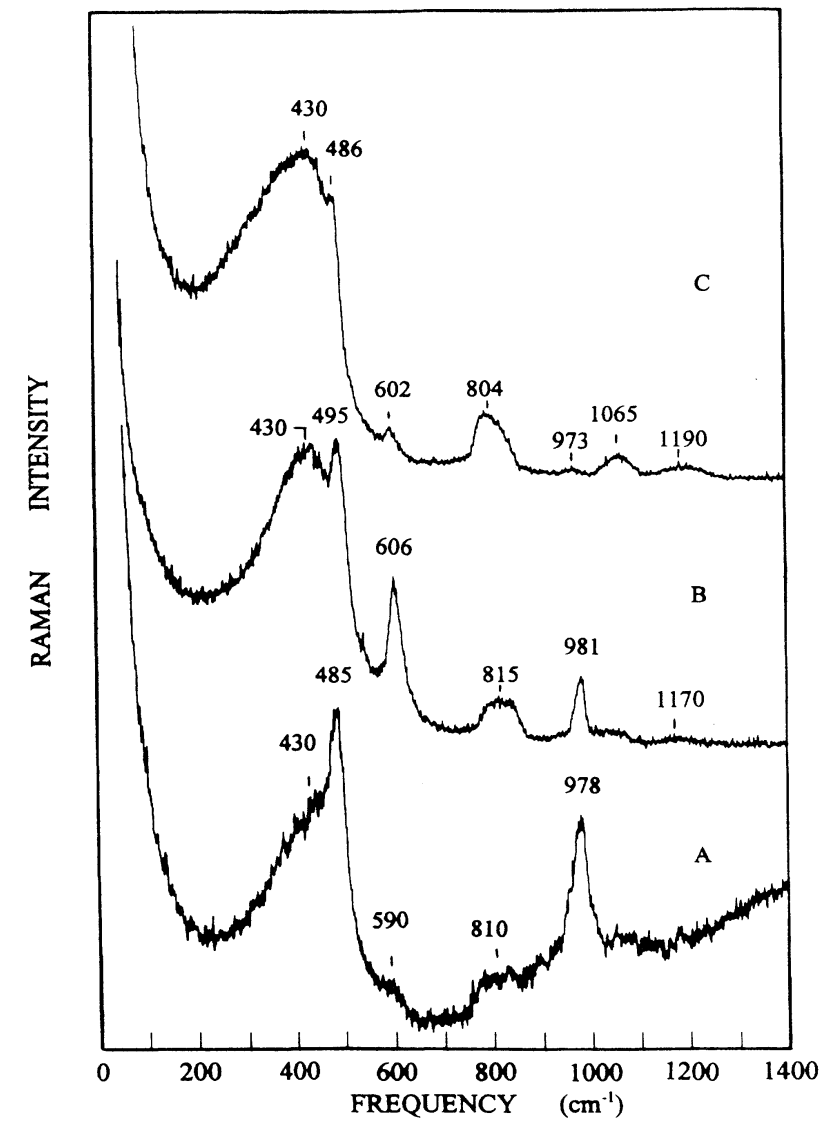

FIG. 3. Raman spectra of $\mathrm{SiO}_{2}$ gels heat treated at different temperatures: $(A)$ air-dried, $(B) 650^{\circ} \mathrm{C}$, and $(C) 1000^{\circ} \mathrm{C}$. 
the spectra of the heat-treated samples $(B, C)$.

The spectrum of the air dried gel [Fig. $3(A)]$ is dominated by the relatively sharp band at $485 \mathrm{~cm}^{-1}$, the broad shoulder at $430 \mathrm{~cm}^{-1}$ and the strong band at 978 $\mathrm{cm}^{-1}$. The band at $430 \mathrm{~cm}^{-1}$ has been attributed to the symmetric stretching vibration of $\mathrm{Si}-\mathrm{O}-\mathrm{Si}$ bridges in fivefold ${ }^{33}$ or sixfold ${ }^{35}$ rings of $\mathrm{SiO}_{4}$ tetrahedra. Scattering at $\sim 980 \mathrm{~cm}^{-1}$ is typical of the $\mathrm{Si}-\mathrm{O}$ stretching vibration of silanol (Si-OH) groups. ${ }^{36}$ The band at $485 \mathrm{~cm}^{-1}$ is referred in the literature as the defect $D_{1}$ and has been assigned by Galeener and co-worker ${ }^{37-39}$ to the symmetric ring breathing mode of four-member rings of $\mathrm{SiO}_{4}$ tetrahedra.

Heat-treating the air-dried gel to $650^{\circ} \mathrm{C}$ [Fig. $3(B)$ ] results in a considerable reduction of the intensities of the $D_{1}\left(485 \mathrm{~cm}^{-1}\right)$ and $\mathrm{Si}-\mathrm{OH}\left(980 \mathrm{~cm}^{-1}\right)$ bands and the development of the band at $605 \mathrm{~cm}^{-1}$. The latter feature is known as defect band $D_{2}$ and has been assigned to the symmetric ring breathing mode of three-member rings of $\mathrm{SiO}_{4}$ tetrahedra. ${ }^{37-39}$ Heat treating at $1000^{\circ} \mathrm{C}$ [Fig. 3(C)] results in further spectral changes. In particular, the reduction in intensity of both $D_{1}$ and $D_{2}$ bands is notable, as well as that characteristic of $\mathrm{SiOH}$ groups. The intensity of the latter band $\left(973 \mathrm{~cm}^{-1}\right)$ in Fig. $3(C)$, although very weak, is indicative of some residual water in the form of silanol groups. Besides the relative intensity enhancement of the $430 \mathrm{~cm}^{-1}$ band, the spectrum in Fig. $3(C)$ also shows the clear development of the asymmetric band at $805 \mathrm{~cm}^{-1}$ (deformation mode of the Si-O-Si network $^{37-39}$ ) and those at 1065 and $1190 \mathrm{~cm}^{-1}$. The latter features correspond to the Raman-active TO components of the $\mathrm{AS}_{1}$ and $\mathrm{AS}_{2}$ modes of the asymmetric stretching of Si-O-Si linkages. ${ }^{25-27}$

It is clearly demonstrated by the evolution of the Raman spectra that increasing heat-treatment temperature causes elimination of the hydroxyl group (in the form of $\mathrm{Si}-\mathrm{OH}$ bonds) and the development of the silicate network. This is presumably effected through condensation of the $\mathrm{Si}-\mathrm{OH}$ bonds into $\mathrm{Si}-\mathrm{O}-\mathrm{Si}$ linkages upon water elimination. Such a process obviously results in gel densification, as manifested also by the increasing infrared reflectivity. Thus, consideration of the Raman spectra has provided a mechanism at a molecular level to understand the reflectivity variation with treatment temperature.

We have attempted to completely eliminate the $\mathrm{Si}-\mathrm{OH}$ groups, and thus increase further the reflectivity of the resulting glass, by annealing samples at $1000^{\circ} \mathrm{C}$ for $3 \mathrm{~h}$. This procedure has resulted in partial crystallization, as shown by the Raman and infrared reflectance spectra in Fig. 4. While the Raman feature at $970 \mathrm{~cm}^{-1}$ has disappeared, new intense and sharp bands at 111, 231, and 417 $\mathrm{cm}^{-1}$ appear superimposed on the glassy $\mathrm{SiO}_{2}$ spectrum. The Raman spectrum of $a$-cristobalite reported by Bates $^{40}$ exhibits its strongest bands at 110, 230, and 416 $\mathrm{cm}^{-1}$ and weak features at 785, 796, 1076, and 1193 $\mathrm{cm}^{-1}$. It is suggested then that the Raman spectrum of Fig. 4 corresponds to a $\mathrm{SiO}_{2}$ gel and/or glass partially crystallized to $a$-cristobalite. Contrary to this observation, the corresponding infrared reflectance spectrum in Fig. 4 appears as that of $a$-cristobalite alone (40). This in- dicates that crystallization starts from the surface of the gels, which is particularly probed by infrared-reflectance spectroscopy.

\section{B. Analysis of the infrared-reflectance spectra}

Additional information regarding the structures of the $\mathrm{SiO}_{2}$ gels and the location of the TO and LO modes can be obtained by further treatment of the reflectivity data. Figures 5 and 6 show the spectra of the imaginary part of the complex dielectric function $\left(\varepsilon^{\prime \prime}\right)$ and of the energyloss function $(-\operatorname{Im}(1 / \varepsilon))$ obtained by Kramers-Kronig analysis, respectively.

As shown in Fig. 5, besides differences in absolute values of $\varepsilon^{\prime \prime}$, which increase from sample $A$ to $C$, frequency shifts and changes in relative intensities also occur. In addition, the $\varepsilon^{\prime \prime}$ spectrum of the air-dried gel shows weak features at $\sim 590$ and $960 \mathrm{~cm}^{-1}$. These bands are very weak or nearly absent in the other spectra. The higher-frequency peak is associated with the stretching vibration of Si-OH groups, ${ }^{36}$ therefore showing the presence of silanol groups in the air-dried gel and their destruction with heat treatment, in agreement with the Raman spectra. The lower-frequency broad peak at $\sim 590 \mathrm{~cm}^{-1}$ was attributed to the rocking motion of the $\mathrm{Si}-\mathrm{OH}$ groups. ${ }^{11}$ However, an alternative assignment to the skeletal vibration of fourfold siloxane rings was re-

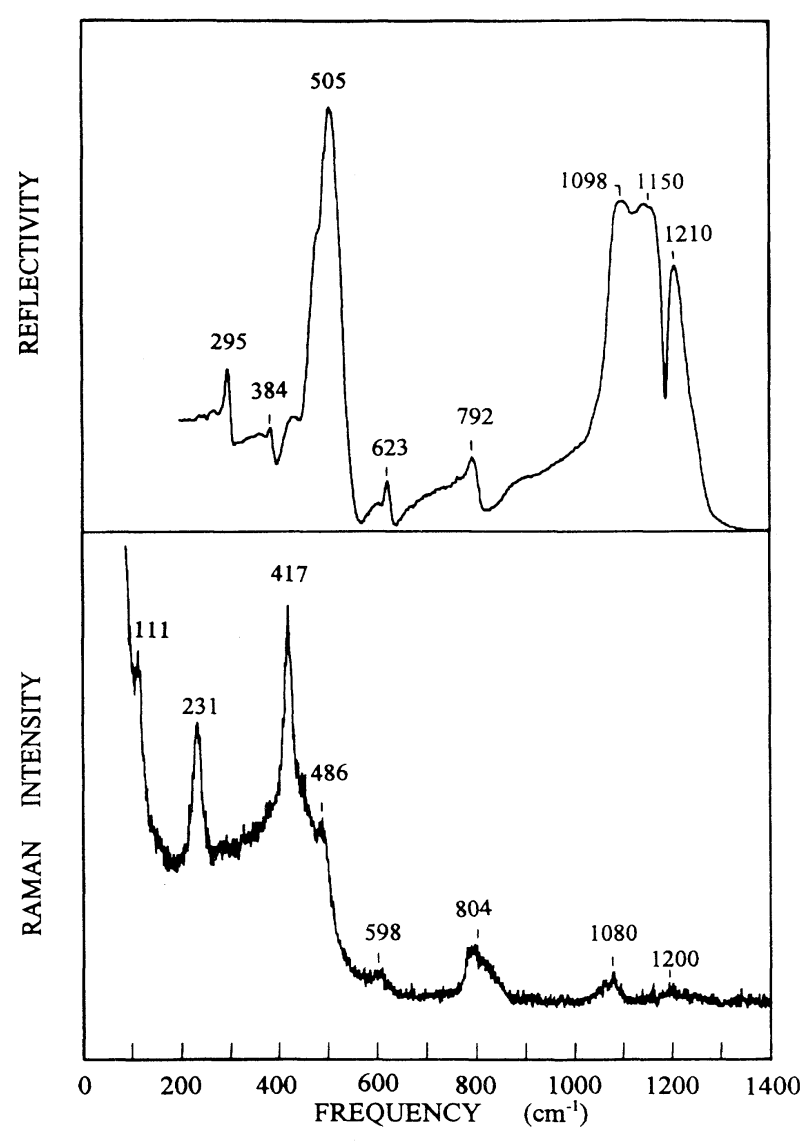

FIG. 4. Raman and infrared reflectance spectra of a sample $C$ annealed at $1000^{\circ} \mathrm{C}$ for $3 \mathrm{~h}$. For details see text. 
cently proposed by Yoshino, Kamiya, and Nasu, ${ }^{12}$ on the basis of a comparative infrared study of cyclic siloxanes and silicate minerals.

As noted before, there is considerable disagreement regarding the origin of the $\sim 1200 \mathrm{~cm}^{-1}$ shoulder in the transmission spectra of thin films of amorphous $\mathrm{SiO}_{2}$. One viewpoint ${ }^{5,11}$ attributes LO character to this shoulder, while the opposite assignment to a TO mode has been also discussed. ${ }^{16,24-27}$ As shown in Fig. 5, the $\varepsilon^{\prime \prime}$ spectra, where peaks are known to originate from TO modes, ${ }^{17}$ exhibit well-defined shoulders at $\sim 1200 \mathrm{~cm}^{-1}$, with intensity much higher than that of vitreous $\mathrm{SiO}_{2} \cdot{ }^{17,19}$ While the relative intensity of this shoulder is decreasing with heat treatment, the total infrared activity in the frequency range $1000-1300 \mathrm{~cm}^{-1}$ remains practically constant. It is found that the spectral area of this frequency range relative to the area of the whole infrared spectrum, takes the values 0,56 for the air-dried gel, and $0.53,0.55$ for the $650^{\circ} \mathrm{C}$ and $1000^{\circ} \mathrm{C}$, respectively. This result shows that the sum of the infrared activities of the bands at $\sim 1100$ and $\sim 1200 \mathrm{~cm}^{-1}$ remains within experimental error constant, while their relative activity varies with heat-treatment temperature. We suggest that this experimental evidence together with the fact that the $\sim 1200 \mathrm{~cm}^{-1}$ shoulder appears clearly in the $\varepsilon^{\prime \prime}$ spectra,

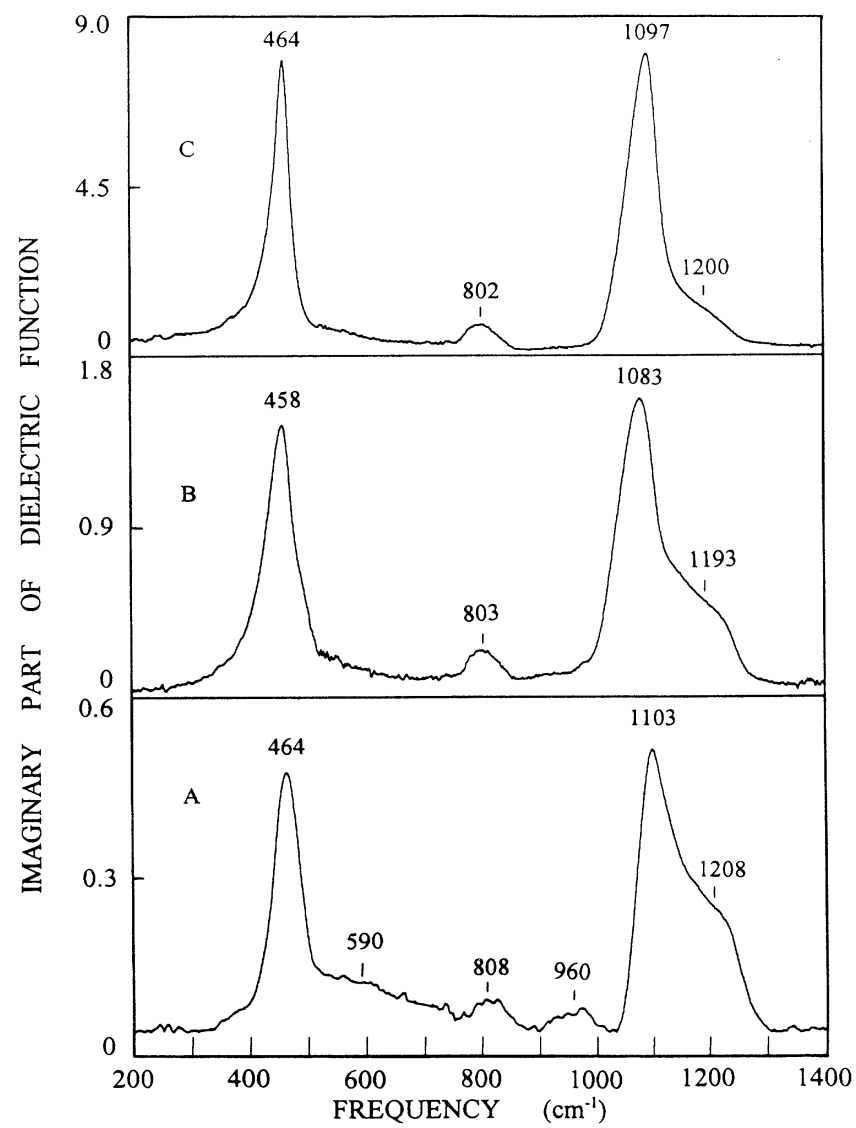

FIG. 5. Spectra of the imaginary part of the complex dielectric function $\left(\varepsilon^{\prime \prime}\right)$ for the $(A)$ air-dried and $(B)$ the heat-treated gels at $650^{\circ} \mathrm{C}$ and $(C) 1000^{\circ} \mathrm{C}$. lend support to the assignment of this feature to the TO component of the $\mathrm{AS}_{2}$ mode. ${ }^{16,25-27}$ As discussed by Kirk $^{25}$ the $\mathrm{AS}_{2}$ mode is optically inactive, but becomes activated by disorder-induced coupling with the strong infrared $\mathrm{AS}_{1}$ mode. Kirk also showed that the overall strength of the coupled modes is constant, and any increase of the strength of the $\mathrm{AS}_{2}$ mode is effected at the expense of the strength of the $\mathrm{AS}_{1}$ mode. The results of this study show that the coupling of these modes is stronger in $\mathrm{SiO}_{2}$ gels, compared to vitreous silica, probably because the $\mathrm{Si}-\mathrm{O}-\mathrm{Si}$ bridges are strained at the surface of the gel pores. ${ }^{14}$

Pronounced differences between the three gel samples studied here can be seen particularly in the highfrequency range $\left(1000-1300 \mathrm{~cm}^{-1}\right)$ of the energy-loss spectra (Fig. 6). The spectrum of the $1000^{\circ} \mathrm{C}$ treated gel [Fig. $6(C)$ ] shows the most intense LO band at 1255 $\mathrm{cm}^{-1}$ with a lower frequency shoulder at $\sim 1170 \mathrm{~cm}^{-1}$ in close similarity with the spectrum of vitreous $\mathrm{SiO}_{2} \cdot{ }^{17,19}$ The situation is reversed in the case of the air-dried gel, the spectrum of which exhibits the stronger band at 1115 $\mathrm{cm}^{-1}$ and a shoulder at approximately $1215 \mathrm{~cm}^{-1}$. The spectrum of the gel treated at $650^{\circ} \mathrm{C}$ [Fig. $6(B)$ ] demonstrates an intermediate case. In view of the trends exhibited by both the energy loss and the $\varepsilon^{\prime \prime}$ spectra, and the previous assignment by Kirk, ${ }^{25}$ we attribute the 1115 ,

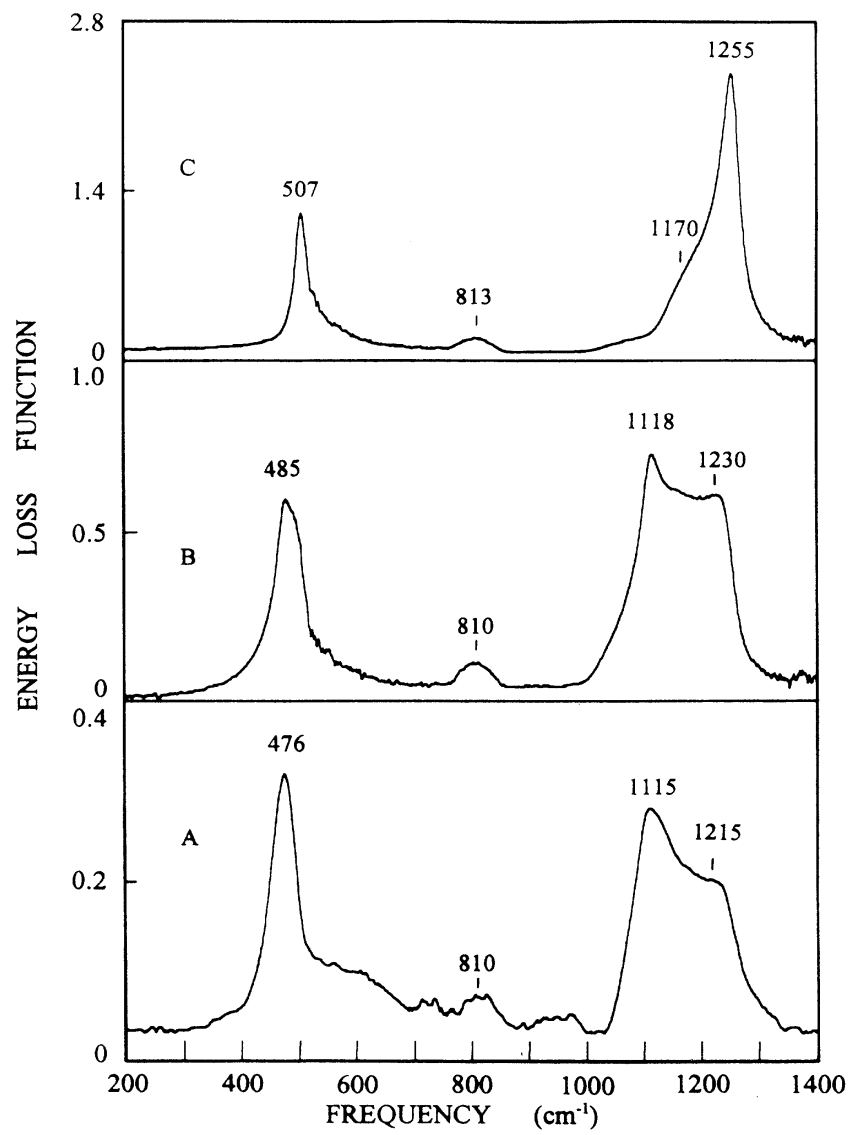

FIG. 6. Energy-loss spectra $(-\operatorname{Im}(1 / \varepsilon))$ of $(A)$ the air-dried gel and $(B)$ the heat-treated gels at $650^{\circ} \mathrm{C}$ and $(C) 1000^{\circ} \mathrm{C}$. 
TABLE I. Frequencies in $\mathrm{cm}^{-1}$ of LO and TO mode and LO-TO splitting for the rocking $(R)$, bending $(B)$, and asymmetric stretching (AS) vibrations of Si-O-Si bridges in silica gels and vitreous silica $\left(v-\mathrm{SiO}_{2}\right)$.

\begin{tabular}{lcrrrrr}
\hline & Mode & $\mathrm{RT}^{\mathrm{a}}$ & $650^{\circ} \mathrm{C}^{\mathrm{a}}$ & $1000^{\circ} \mathrm{C}^{\mathrm{a}}$ & $v-\mathrm{SiO}_{2}{ }^{\mathrm{b}}$ & $v-\mathrm{SiO}_{2}{ }^{\mathrm{c}}$ \\
\hline$R$ & TO & 464 & 458 & 464 & 448 & 457 \\
& LO & 476 & 485 & 507 & 504 & 507 \\
$B$ & LO-TO & +12 & +27 & +43 & +56 & +50 \\
& TO & 808 & 803 & 802 & 800 & 810 \\
& LO & 810 & 810 & 813 & 824 & 820 \\
$\mathrm{AS}_{1}$ & LO-TO & +2 & +7 & +11 & +24 & +10 \\
& TO & 1103 & 1083 & 1097 & 1063 & 1076 \\
& LO & 1215 & 1230 & 1255 & 1260 & 1256 \\
$\mathrm{AS}_{2}$ & LO-TO & +112 & +147 & +158 & +197 & +180 \\
& TO & 1208 & 1193 & 1200 & & 1200 \\
& LO & 1115 & 1118 & 1170 & & 1160 \\
& LO-TO & -93 & -75 & -30 & & -40 \\
\hline \hline
\end{tabular}

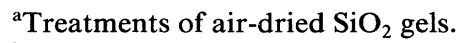

${ }^{b}$ Frequencies were estimated from the $\varepsilon^{\prime \prime}$ and $-\operatorname{Im}(1 / \varepsilon)$ spectra reported by Galeener and Lucovsky (Ref. 17).

${ }^{\mathrm{c}}$ Frequencies reported by Kirk (Ref. 25) for absorption spectra measured at oblique incidence $\left(60^{\circ}\right.$ offnormal) with $p$-polarized infrared radiation.

1118 , and $1170 \mathrm{~cm}^{-1}$ peaks in the $-\operatorname{Im}(1 / \varepsilon)$ spectra to the $\mathrm{LO}$ components of the $\mathrm{AS}_{2}$ modes, with TO partners at $\sim 1208,1193$, and $1200 \mathrm{~cm}^{-1}$, respectively (Table I). Along these lines, the features at $\sim 1215,1230$, and at $1255 \mathrm{~cm}^{-1}$ (Fig. 6) are assigned to the LO components of the $\mathrm{AS}_{1}$ modes, with TO pairs at 1103, 1083, and 1097 $\mathrm{cm}^{-1}$, respectively (Table I).

As shown in Table I, the LO and TO modes for the $\mathrm{AS}_{1}$ vibration exhibit the usual interspersion, since the frequency of the LO mode is higher than that of the TO mode. However, the LO-TO frequency splitting is found inverted for the $\mathrm{AS}_{2}$ vibration. An explanation for such an effect was provided by Kirk. ${ }^{25}$ It was demonstrated theoretically that when the frequencies of a LO-TO pair $\left(\mathrm{AS}_{2}\right)$ are sandwiched between the frequencies of another LO-TO pair $\left(\mathrm{AS}_{1}\right)$ then coupling between the two modes heads to inversion of the LO-TO frequencies of the sandwiched pair. It is seen in Table I that this LO-TO inversion is stronger for the $\mathrm{AS}_{2}$ mode of the air-dried silica gel, due presumably to a stronger coupling with the corresponding $\mathrm{AS}_{1}$ mode.

Location of the LO and TO frequencies for the rocking $(R)$ and bending $(B)$ vibrations of $\mathrm{Si}-\mathrm{O}-\mathrm{Si}$ bridges is straightforward from the $\varepsilon^{\prime \prime}$ and $-\operatorname{Im}(1 / \varepsilon)$ spectra. The results are given in Table $\mathrm{I}$, where data for vitreous $\mathrm{SiO}_{2}$ and LO-TO splittings are also included. It is observed that the LO-TO splitting of the $R, B$, and $\mathrm{AS}_{1}$ modes increases systematically upon increasing the heat-treatment temperature of the gel, the behavior of the $1000^{\circ} \mathrm{C}$ treated gel approaching that at $v-\mathrm{SiO}_{2}$. This very interesting effect of variable LO-TO splitting is observed for the first time to the best of our knowledge, and can be understood on the basis of the structure of these silica materials. Since the LO-TO splitting in crystalline, as well as glassy materials, ${ }^{17,19}$ originates from long-range Coulombic interactions, these results suggest that the long-range Coulombic forces increase with thermal treatment of gels. As shown by Raman and infrared spectra, the airdried gels and to a smaller extent that heated at $650^{\circ} \mathrm{C}$, do not have a completely cross-linked silicate network due to the presence of network-terminating $\mathrm{Si}-\mathrm{OH}$ groups. As a result the range of the Coulombic forces is reduced resulting in smaller LO-TO splitting. Upon increasing the temperature of treatment, the $\mathrm{Si}-\mathrm{OH}$ groups are condensed to $\mathrm{Si}-\mathrm{O}-\mathrm{Si}$ bridges, a process which enhances the network connectivity and consequently the range of the Coulombic forces. This is apparently manifested by the larger LO-TO splittings at higher heattreatment temperatures.

\section{CONCLUSIONS}

The structure of $\mathrm{SiO}_{2}$ materials, prepared by the sol-gel technique and heat treated at $650{ }^{\circ} \mathrm{C}$ and $1000^{\circ} \mathrm{C}$ was investigated by infrared reflectance and Raman spectroscopies. Large variations of infrared reflectivity with heat-treatment temperature were observed and attributed to a gradual densification of the porous structure of the materials. It was shown by both spectroscopies that this densification is effected by condensation of $\mathrm{Si}-\mathrm{OH}$ groups into Si-O-Si bridging units, which serve to crosslink the silicate network.

Kramers-Kronig analysis of the infrared reflectance spectra allowed the location of the transverse-optic (TO) and longitudinal-optic (LO) modes of the rocking $(R)$, bending $(B)$, and asymmetric stretching (AS) vibrations of $\mathrm{Si}-\mathrm{O}-\mathrm{Si}$ bridges. It was shown that the high frequency $\left(1000-1300 \mathrm{~cm}^{-1}\right)$ parts of the $\operatorname{TO}\left(\varepsilon^{\prime \prime}\right)$ and $\operatorname{LO}(-\operatorname{Im}(1 / \varepsilon))$ spectra can be well understood on the basis of two LO-TO pairs for the AS vibration of the $\mathrm{Si}-\mathrm{O}-\mathrm{Si}$ bridges, as proposed by a number of previous works. ${ }^{16,25-27}$ One pair arises from the in-phase mode $\left(\mathrm{AS}_{1}\right)$ and the other from the out-of-phase mode $\left(\mathrm{AS}_{2}\right)$ of the AS vibration, while coupling between these two 
modes results in the inversion of LO-TO splitting for the $\mathrm{AS}_{2}$ mode. ${ }^{25}$ This inversion was found to decrease with increasing heat-treatment temperature of the gel. Heat treating was also found to cause the increase of the LOTO splitting for the $R, B$, and $\mathrm{AS}_{1}$ modes. This effect was attributed to the strengthening of the long-range Coulombic interactions, due to increasing network crosslinking through formation of $\mathrm{Si}-\mathrm{O}-\mathrm{Si}$ bridges.

The results of this study are quite useful for the interpretation of the infrared transmission spectra of thin films of $\mathrm{SiO}_{2}$ gel materials. In particular it was discussed that the shoulder at $\sim 1200 \mathrm{~cm}^{-1}$, measured in absorp- tion spectra with normal incidence, should be attributed to the TO mode of the $\mathrm{AS}_{2}$ vibration, rather than to the activation of an LO mode as proposed in previous studies.

\section{ACKNOWLEDGMENTS}

Support of this work by EEC and the General Secretariat for Research and Technology, Greece, through the STRIDE (No. 130) project is gratefully acknowledged. The authors are also grateful to Dr. G. D. Chryssikos for helpful discussion of this paper.
${ }^{1}$ S. H. Wang, C. Campbell, and L. L. Hench, in Ultrastructure Processing of Advanced Ceramics, edited by J. D. Mackenzie and D. R. Ulrich (Wiley, New York, 1988), p. 145.

${ }^{2}$ C. J. Brinker, A. J. Hurd, G. C. Frye, R. R. Schunk, and C. S. Ashley, J. Ceramic Soc. Jpn. 99, 843 (1991).

${ }^{3}$ For a recent review article on the methods employed to investigate the gel to glass transition see P. F. James, J. Non-Cryst. Solids 100, 93 (1988).

${ }^{4}$ M. Decottignies, J. Phalippou, and J. Zarzycki, J. Mater. Sci. 13, 2605 (1978).

${ }^{5}$ A. Bertoluzza, C. Fagnano, M. A. Morelli, V. Gottardi, and M. Guglielmi, J. Non-Cryst. Solids 48, 117 (1982).

${ }^{6}$ C. J. R Gonzalez-Oliver, P. F. James, and H. Rawson, J. NonCryst. Solids 48, 129 (1982).

${ }^{7}$ F. Orgaz and H. Rawson, J. Non-Cryst. Solids 82, 57 (1986).

${ }^{8}$ A. Duran, C. Serna, V. Fornes, and J. M. Fernandez Navaro, J. Non-Cryst. Solids 82, 69 (1986).

${ }^{9}$ D. L. Wood and E. M. Rabinovich, J. Non-Cryst. Solids 82, 171 (1986).

${ }^{10}$ D. L. Wood and E. M. Rabinovich, Appl. Spectroscopy 43, 263 (1989).

${ }^{11}$ R. M. Almeida and C. G. Pantano, J. Appl. Phys. 68, 4225 (1990).

${ }^{12}$ H. Yoshino, K. Kamiya, and H. Nasu, J. Non-Cryst. Solids 126, 68 (1990).

13J. C. Ro and I. J. Chung, J. Non-Cryst. Solids 130, 8 (1991).

${ }^{14}$ R. M. Almeida, J. A. Guiton, and C. G. Pantago, J. NonCryst. Solids 121, 193 (1990).

${ }^{15}$ I. Simon and H. O. McMahon, J. Am. Ceram. Soc. 36, 160 (1953).

${ }^{16}$ P. H. Gaskell and D. W. Johnson, J. Non-Cryst. Solids 20, 153 (1976); 20, 171 (1976).

${ }^{17}$ F. L. Galeener and G. Lucovsky, Phys. Rev. Lett. 37, 1474 (1976).

${ }^{18}$ C. A. Murray and T. J. Creytak, Phys. Rev. B 20, 3368 (1979); J. Chem. Phys. 71, 3355 (1979).

${ }^{19}$ F. L. Galeener, A. J. Leadbetter, and M. W. Stringfellow, Phys. Rev. B 27, 1052 (1983).

${ }^{20}$ H. R. Philipp, J. Appl. Phys. 50, 1053 (1979).
${ }^{21}$ K. Hübner, L. Schumann, A. Lehmann, H. H. Vajen, and G. Zuther, Phys. Status Solidi B 104, K1 (1981).

${ }^{22}$ M. Nakamura, Y. Mochizuki, K. Usami, Y. Itoh, and T. Nozaki, Solid State Commun. 50, 1079 (1984).

${ }^{23}$ I. W. Boyd, Appl. Phys. Lett. 51, 418 (1987); S. H. Wang, C. Campbell, and L. L. Hench, in Ultrastructure Processing of Advanced Ceramics (Ref. 1), p. 145.

${ }^{24}$ J. E. Olsen and F. Shimura, J. Appl. Phys. 66, 1353 (1989).

${ }^{25}$ C. T. Kirk, Phys. Rev. B 38, 1255 (1988).

${ }^{26}$ P. G. Pai, S. S. Chao, Y. Takagi, and G. Lucovsky, J. Vac. Sci. Technol. A 4, 689 (1986).

${ }^{27}$ G. Lucovsky, C. K. Wong, and W. B. Pollard, J. Non-Cryst. Solids 59+60, 839 (1983).

${ }^{28}$ D. W. Berreman, Phys. Rev. 130, 2193 (1963).

${ }^{29}$ D. M. Krol and J. G. Lierop, J. Non-Cryst. Solids 63, 131 (1984).

${ }^{30}$ L. L. Hench, in Science of Ceramic Chemical Processing, edited by L. L. Hench and D. R. Ulrich (Wiley, New York, 1986), p. 52.

${ }^{31}$ E. I. Kamitsos, A. P. Patsis, M. A. Karakassides, and G. D. Chryssikos, J. Non-Cryst. Solids 126, 52 (1990); E. I. Kamitsos, A. P. Patsis, and G. D. Chryssikos, J. Non-Cryst. Solids 152, 246 (1993).

${ }^{32}$ V. Gottardi, M. Guglielmi, A. Bertoluzza, C. Fagnano, and M. A. Morelli, J. Non-Cryst. Solids 63, 71 (1984).

${ }^{33}$ J. C. Brinker, B. C. Bunker, D. R. Tallant, and K. J. Ward, J. Chim. Phys. 83, 851 (1986).

${ }^{34}$ C. J. Brinker, R. J. Kirkpatrick, D. R. Tallant, B. C. Bunker, and B. Montez, J. Non-Cryst. Solids 99, 418 (1988).

${ }^{35}$ S. P. Mukherjee and S. K. Sharma, J. Am. Ceram. Soc. 69, 806 (1986).

${ }^{36}$ R. H. Stolen and G. E. Walrafen, J. Chem. Phys. 64, 2623 (1976).

${ }^{37}$ F. L. Galeener, Solid State Commun. 44, 1037 (1982).

${ }^{38}$ F. L. Galeener and A. E. Geissberger, Phys. Rev. B 27, 6199 (1983).

${ }^{39}$ F. L. Galeener, J. Non-Cryst. Solids 49, 53 (1982); 71, 373 (1985).

${ }^{40}$ J. B. Bates, J. Chem. Phys. 57, 4042 (1972). 